\title{
Oral and maxillofacial anatomical structures acknowledgment through cone beam computed tomography images - a teaching practice experience
}

\author{
Solange Kobayashi-Velasco*; Fernanda Cristina Sales Salineiro**; Ivan Onone Gialain**; Wellington \\ Hideaki Yanaguizawa*; Marcelo Gusmão Paraiso Cavalcanti*** \\ * DDS, MSc., Stomatology Department, Universidade de São \\ Paulo School of Dentistry \\ ** DDS, Ph.D., Stomatology Department, Universidade de São \\ Paulo School of Dentistry, Program on Integrated Dental \\ Sciences, Faculty of Dentistry, University of Cuiabá \\ *** DDS, Ph.D., Associate Professor III, Stomatology \\ Department, Universidade de São Paulo School of Dentistry
}

Received July 18, 2019. Approved January 6, 2020.

\begin{abstract}
This study proposed to report a cone beam computed tomography (CBCT) teaching methodology applied to Dental School students by assessing mid-term and end-term exams correct recognition of anatomical structures. Students were instructed on oral and maxillofacial anatomical structures and clinical applications of CBCT imaging through lectures and hands-on classes, comprising forty-five hours of classes. They were submitted to two tests, the first one at mid-term and the second one at end-term. Anatomical structures recognition test scores (three variables: 1) name, 2) side - left/right and 3) multiplanar reconstructions (MPR) orthogonal images identification) were compared to verify if learning improvement occurred. Medians and Wilcoxon tests compared mid with end term exams. Median values for variable 1 were 6.0 (mid-term) and 8.0 (end-term). With regard to variable 2, median values ranged from 9.0 (mid-term) to 10.0 (end-term). When variable 3 results were analyzed, both mid-term and end-term medians were 10.0 . Wilcoxon test $(\mathrm{p}<0.05)$ showed significant differences when comparing mid-term and end-term exams in each of the three categories. Linear correlations were established among the three categories. Correlations were statistically significant for two associations ("anatomical structure name" with "anatomical structure side", and "anatomical structure name" with "MPR images"). Predoctoral dental school students presented a comprehensive improvement in terms of correctly recognizing anatomical structures name and side, as well as MPR images when comparing mid-term and end-term tests.

Descriptors: Education, Dental. Cone-Beam Computed Tomography. Radiology. Medical Informatics.
\end{abstract}




\section{INTRODUCTION}

Cone-beam computed tomography (CBCT) is an imaging exam that uses $\mathrm{X}$-rays to generate three-dimensional images, allowing the observation of a part of the human body in three different perspectives through multiplanar reconstruction (MPR) (axial, coronal and sagittal images simultaneously). Nowadays, worldwide commercial distribution of this machine ${ }^{1}$ allows its use in various fields of Dentistry (surgery, implant dentistry, endodontics, orthodontics, oral diagnostics, among others) $)^{2-4}$.

According to American Academy of Oral and Maxillofacial Radiology (AAOMR) guidelines $^{5}$, the practitioner has to select the appropriate imaging procedure based on each clinical situation, and also be able to interpret these images. In other words, CBCT exams should be prescribed only after periapical, occlusal and panoramic radiographies do not supply enough information to reach diagnosis, treatment planning and prognosis for the patient ${ }^{6}$.

A study published in 2012 determined that the majority of predoctoral students in the United States of America (USA), United Kingdom (UK) and Australia were instructed on 3D anatomical structures from CBCT imaging as part of their curriculum. CBCT imaging interpretation training was provided in about half of the Dental Schools in the USA and Australia, and in one-third in the UK schools ${ }^{7}$. Adibi et al. $^{1}$ stated that CBCT learning as a whole had to be promoted in the predoctoral curriculum. This research group suggested that anatomy in CBCT imaging could be introduced at the first year, and that oral radiology course might teach radiation risks, fundamentals and principles of CBCT imaging, how to select the equipment and suitable protocol for each clinical situation, interpretation of anatomical structures and their variations, artifacts influence as well as interpretation and manipulation of CBCT images and softwares.
Also, they recommended that the practitioner should always seek an expert (oral and maxillofacial radiologist) opinion in those cases that he/she had questionings.

In the literature, we have not identified studies that have provided quantitative information as to the identification of anatomical structures, image side and MPR images from CBCT scans by undergraduate students. Thus, the aim of our study was to evaluate these students CBCT learning progress by assessing mid-term and end-term exams, with regard to correct recognition of anatomical structure and MPR images generated on CBCT volumes.

\section{METHODS}

This study was performed one year after the students were evaluated and was approved by Universidade de São Paulo School of Dentistry Institutional Review Board (IRB) under the protocol number 67447317.0.0000.0075. Only students that signed a consent form were included in this research. Out of the 138 students registered in 2016 in two classes (one class had fifty and the other, eighty-eight students), seventy-five (54\%) agreed to participate in this study.

\section{Curriculum and subject design}

Oral Radiology subjects are taught in three semesters at our institution. In the last year of Dental School, the students receive information on digital imaging and interpretation. This subject comprehends forty-five hours of class.

In 2016, the third semester of Oral Radiology syllabus was revised and hands-on classes were added in addition to lectures. The first two introductory lectures lasted about four hours, and the subsequent ones ("short lectures") lasted about ninety minutes. Each "short lecture" was followed by a two-hour and thirty-minutes hands-on class. The "short lecture" presented on a certain week had a complimentary hands-on class 
on the subsequent week. Lectures comprised CBCT principles, prescription and interpretation of CBCT images in various fields of Dentistry (surgery, implant dentistry, endodontics, orthodontics, pathology, trauma, and temporomandibular joint analysis) and other digital imaging methods used in Dentistry (digital periapical radiographies, ultrasound, bone densitometry, PET-CT and magnetic resonance imaging).

Previously to the first hands-on class, the students were directed to download a free of cost CBCT viewer software (Imaging Studio, Anne Solutions, São Paulo, Brazil) to their notebooks. The paid version of the same software allowed the instructor to transform DICOM images into a proprietary file that could be analyzed at the free version one. One week before each hands-on class, the students received two files by e-mail: the first one containing an Imaging Studio proprietary file (CBCT volume images) that would be analyzed at the upcoming class and the second one, a guided study in PDF (Adobe Acrobat, Adobe, San Jose, CA, USA) format with all the anatomical structures and/or clinical situations that would be identified during the class. Hence, they were able to manipulate the images beforehand and come to the class with their questions; also, these files could be employed for at-home study. Image files belonged to our institution CBCT database and were anonymized before they were sent to the students (figure 1).

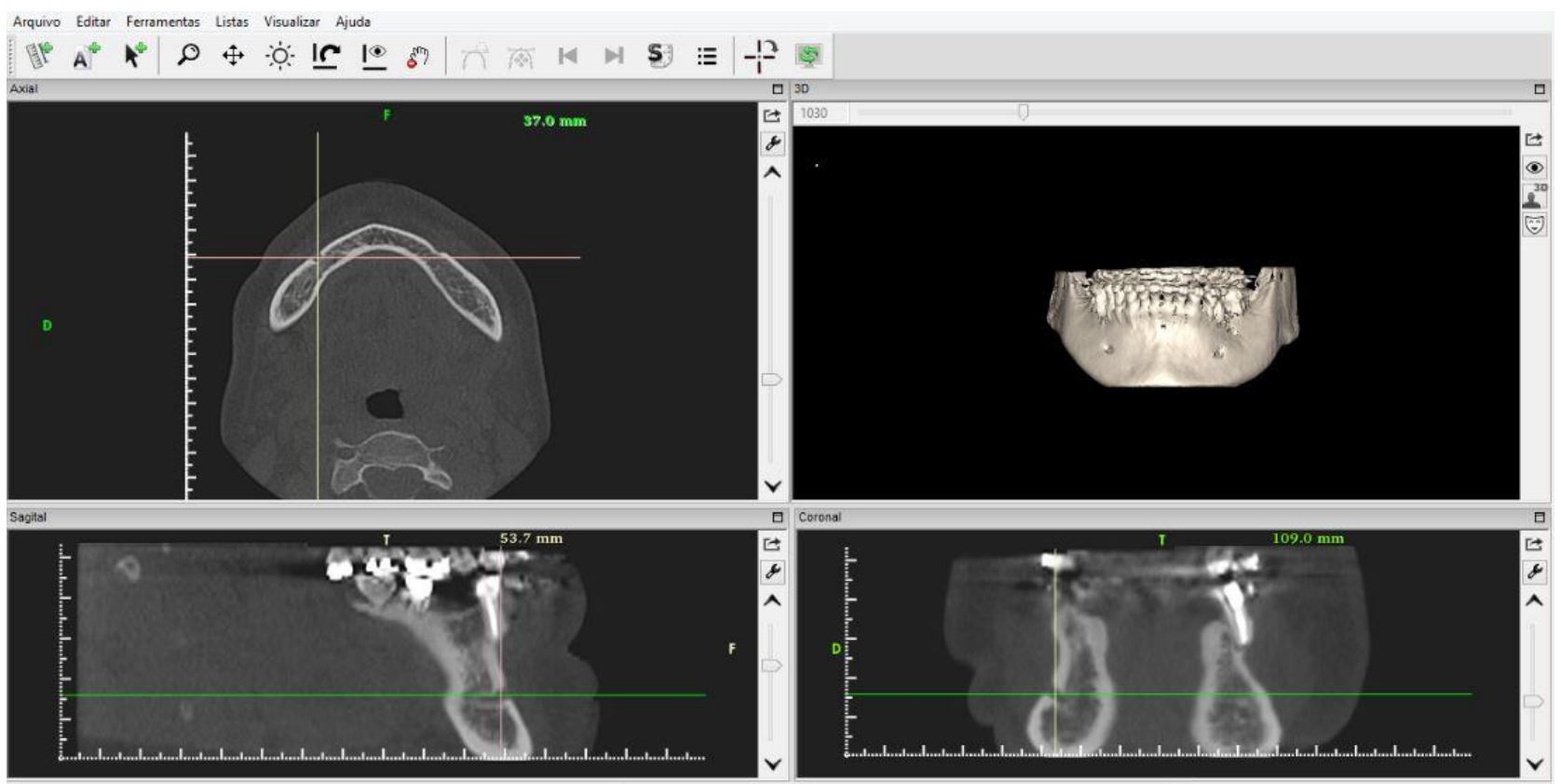

Figure 1. Computer screen depicting the hands-on CBCT images analyzed by the students. Axial, Sagittal, Coronal and 3D reconstruction images. The structure depicted is "mentual foramen, right side"

For the hands-on classes, students brought their personal notebooks to a classroom equipped with eight 42" screens (LG30R, LG, Busan, South Korea) that were connected to the instructor's computer. At the class, the students received training on the software tools and were granted one hour to analyze the items provided at the guided study with the aid of the CBCT viewer software. At this part of the class, the instructor and his assistants (Master's and Ph.D. students 
with experience in CBCT images) provided the predoctoral students with individualized directions, according to their questions and needs.

Thereafter, the instructor mirrored his computer to the screens so that the students would be able to follow his findings along with his explanations. Additional questions were discussed with the instructor and his assistants. Furthermore, the students were encouraged to use screen capture tools of their choice to catalog CBCT images for at-home reviews.

\section{Anatomical structures knowledge assessment}

The students were submitted to two tests (one at mid-term and the other at the end of term), which evaluated lecture and hands-on learning independently. The anatomical structure knowledge tests were based on the hands-on classes. These evaluations consisted of identification of the anatomical structure (name and side - left or right), and the CBCT-MPR images (sagittal, coronal and/or axial) that represented the structure. In total, the students had to identify ten anatomical structures that were previously compiled via PowerPoint (Microsoft, Seattle, WA, USA). Each PowerPoint slide contained a sequential number (from 1 to 10) and two CBCT images (sagittal and/or coronal and/or axial) with the anatomical structure pointed with an arrow (figure 2), similarly to a study published by Murakami et $a l{ }^{8}$. The images were projected at a classroom screen and the students received an answer form (numbered from 1 to 10 ) to fill out with the anatomical structure name, the side (left or right) in which the anatomical structure was located and the CBCT MPR images in which the structure was depicted. The students had two minutes to visualize each slide, identify the anatomical landmark along with the corresponding CBCT MPR images, and write down their answers at the form.

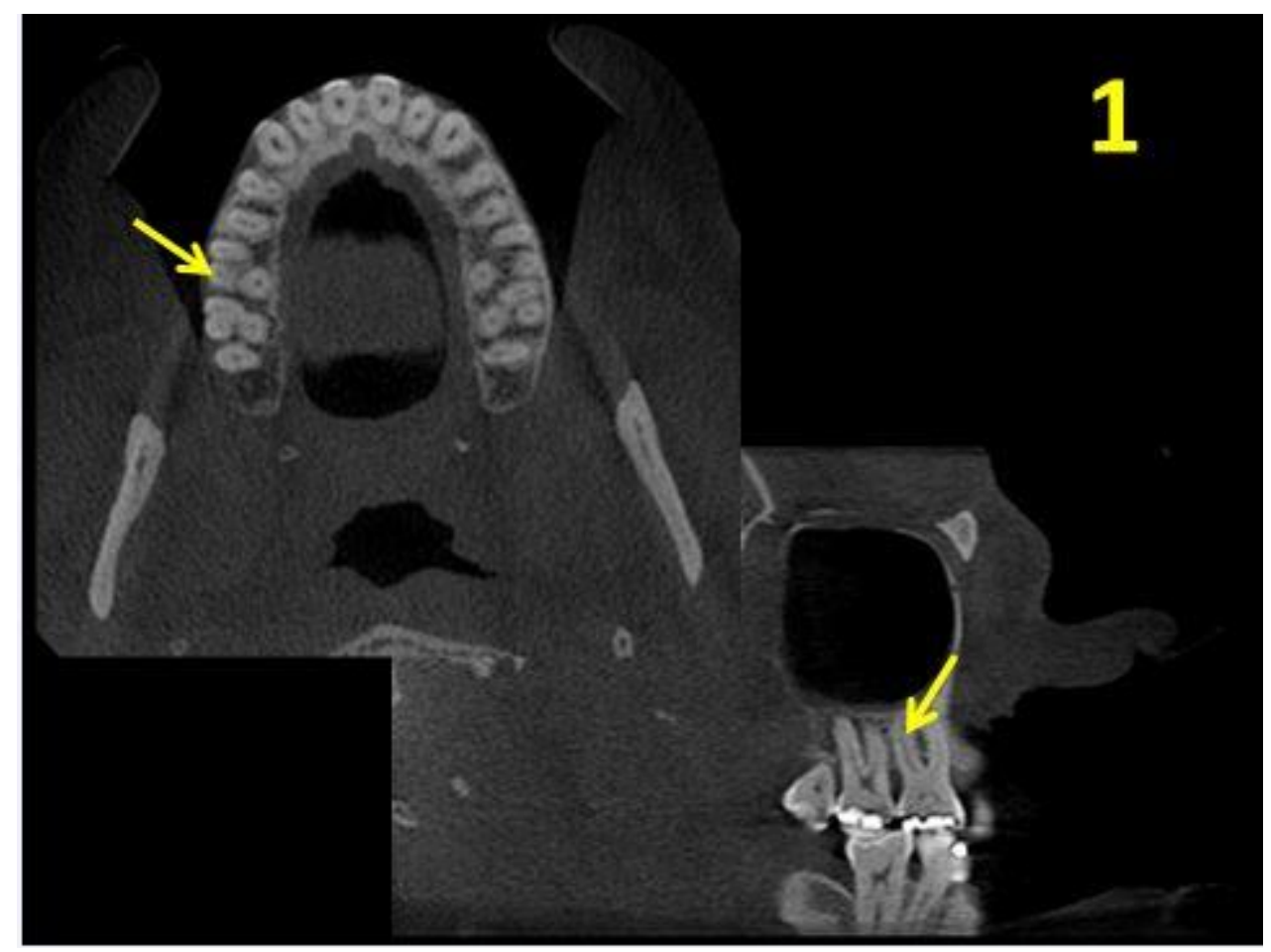

Figure 2. PowerPoint slide as used in mid-term and end-term exams. Yellow arrow points at the structure to be described at the answer sheet. Correct answer: tooth 16 - distobuccal root. Right side. Axial and sagittal images 


\section{Statistical analyses}

Only anatomical structure knowledge tests were assessed in this study. Statistical analyses were performed based on the students' answers. The reference standard (correct answer) was compared with the student's response separately in three categories: anatomical structure name, anatomical structure side (left or right) and CBCT MPR images (axial, coronal and/or sagittal). For each exam (mid-term and end-term separately), every student received a score from 0 to 10 corresponding to the amount of correct answers, for the three above mentioned categories independently. All data were inserted into an Excel (Microsoft, Seattle, WA, USA) spreadsheet and transferred to BioEstat 5.3 software (Instituto Mamirauá, Belém. PA, Brazil). Lilliefors test was applied to assess normality. Descriptive statistics and Wilcoxon tests were performed between midterm and end-term answers to evaluate if a learning progress occurred. Additionally, linear correlation coefficients were determined among the three categories.

\section{RESULTS}

Table 1 portrays medians and Wilcoxon tests for the three categories, in both exams. Median values for "anatomical structure name" were 6.0 for the mid-term and 8.0 for end-term exams. Wilcoxon test demonstrated that a significant statistical difference was determined between mid-term and end-term exams. Concerning "anatomical structure side", median values ranged from 9.0 (mid-term) to 10.0 (endterm). Wilcoxon test $\mathrm{p}$ value was 0.0005 , expressing an improvement in recognizing the correct side presented to the students during the exams. When MPR images were analyzed, both mid-term and end-term medians were 10.0. However interquartile deviations varied from 2.0 (mid-term) to 0.0 (end-term) and Wilcoxon test pvalue was 0.0135 , which implies that a progress occurred in terms of identifying the correct MPR images.

Table 1. Median and Interquartile deviation (ID) for categories ASN, ASS and MPR images, and Wilcoxon tests $\mathrm{p}$ values (two-tailed)

\begin{tabular}{llll}
\hline & $\begin{array}{l}\text { Anatomical structure } \\
\text { - name (ASN) }\end{array}$ & $\begin{array}{l}\text { Anatomical structure } \\
\text { - side (ASS) }\end{array}$ & MPR images \\
\hline Mid-term & $6.0($ ID 1.5)* & 9.0 (ID 2.0)* & 10.0 (ID 2.0)* \\
End-term & $8.0($ ID 2.0)* & $10.0($ ID 1.0)* & 10.0 (ID 0.0)* \\
Wilcoxon tests p values (two-tailed) & $<0.0001$ & 0.0005 & 0.0135 \\
\hline
\end{tabular}

$* \mathrm{p}$ values $<0.05$ for Lilliefors tests

Linear correlation coefficients among the three categories were calculated. Each category was represented by a series of numbers resulting from end-term score subtracting mid-term score, for every student. Correlations were statistically significant for two associations ("anatomical structure name" with "anatomical structure side", and "anatomical structure name" with "MPR images") (table 2).

Table 2. Linear correlation coefficients for each correlation category

\begin{tabular}{lll}
\hline & Anatomical structure - side & MPR images \\
\hline Anatomical structure- name & $0.2448^{*}$ & $0.2725^{*}$ \\
MPR images & 0.1936 & - \\
\hline
\end{tabular}

$* \mathrm{p}$ values $<0.05$ 


\section{DISCUSSION}

A few studies evaluated CBCT learning in Dental Schools predoctoral courses ${ }^{1,7,9,10}$. None of these studies, however, evaluated and compared the students test scores and performance over the semester while providing both online and in-class learning. According to our findings, a significant improvement was observed between mid-term and end-term exams. Anatomical structure names demonstrated a substantial knowledge increase between mid-term and end-term exams (2.0 median variation). This may be explained by the fact that the hands-on classes were based on clinical cases during the term second half. Hence, the students used their anatomical structures identification ability to interpret CBCT images in clinical situations, presenting an improvement at this aspect.

Several studies in Medicine assessed 3D learning methods in the Radiology field. Slanetz et $a l .{ }^{11}$ characterized students that were born between 1982 and 2000 as more inclined to use technology while studying. Besides, they described that this generation enjoys interaction with other people and have a shorter attention span. According to Machado et al. ${ }^{12}$, predoctoral medical students believed that CT and MRI constituted supplemental learning materials at anatomy learning. Therefore, we believe that our curriculum teaching methodology, with the addition of a computer-based learning approach, may have contributed to a good performance by the students as far as identifying anatomical structures and MPR images.

Two studies ${ }^{13,14}$ quantitatively assessed the anatomical structure recognition by using software that provided volumetric images and both produced superior outcomes on the groups that were exposed to computed tomography $2 \mathrm{D}$ images only, thus establishing the importance of a three-dimensional analysis for anatomical structure identification. A study developed by
Ravesloot et al. ${ }^{15}$ assessed students' perception over the use of volumetric images and determined that CT images are more favorable than radiographies as far as identifying anatomical structures; a similar study was conducted by Torres et al. ${ }^{16}$, developing comparable outcomes. These studies reinforce the importance of anatomical structures identification by means of $\mathrm{CT}$, thus corroborating our findings.

At the mid-term exams, there were specific cases in which the students demonstrated difficulty in identifying the correct side (left or right). Thus, after these exams results, these students were individually instructed and presented a progress towards the end-term exams (1.0 median variation improvement for all the students).

MPR images correct recognition depicted a slight improvement between mid-term and endterm tests (interquartile deviation ranged from 2.0 in mid-term to 0.0 in end-term exams). The two MPR images presented to the students during the exam at the PowerPoint presentation were the ones that represented more accurately the anatomical structure. Overall, the students excelled in this category in both examinations, with a few misidentifications between coronal and sagittal images observed.

Linear correlation coefficients were selected to demonstrate improvement associations among the three categories ("anatomical structure name", "anatomical structure side" and "MPR images"). As previously described, there was a statistically significant relationship between anatomical structure name with both anatomical structure side and MPR images recognition, also demonstrating that the classes after mid-term evaluation helped the students with the overall improvement of their knowledge.

We believe that the availability of guided studies combined with CBCT volume files that were provided for the students contributed for 
their performance at the mid-term exam and for their progress at the end-term exam in all three categories. Furthermore, screenshots produced by the students supplied them with extra information for at-home studying.

Al-Rawi et $a l .{ }^{17}$ compared web-based learning by dental students and their improvement. In their study, the correct answer was provided based on multiple-choice questions, which, in our opinion, increases the likelihood of the student in terms of delivering the right answer. Our study generally asked for the written description of an "anatomical structure name", the "anatomical structure side" (each student had a $50 \%$ probability of providing a correct answer) and "MPR images" (the answer was considered as correct only if both MPR images were precisely provided). Thus, it is our belief that in regard with anatomical structure name, our research furnished more accurate information as to the students' knowledge than the study above mentioned.

Hands-on classes (CBCT volume analyses and PDF guided studies supplemented by instructors' assistance), in our opinion, compose a good learning method. We feel that individual attention to predoctoral students is necessary to encourage their questionings according to their personal needs. Thus, we believe that on top of lectures, individual hands-on tutoring is essential to expand their knowledge over CBCT.

We understand that this learning experience has allowed the students to start practicing dentistry with more knowledge and confidence over all aspects of CBCT imaging. AAOMR guidelines $^{5}$ and at least one research group ${ }^{1}$ state that every professional must have received training on CBCT imaging during his/hers predoctoral year. During the semester, we encouraged the students to pursue this improvement and we presume that, based on our results, we have achieved this purpose.

The methodology employed at our institution may be adapted to be included at any Dental School curriculum, from beginning to end. Each institution may select a combination of software and guided study file to send to the students before the hands-on class. The students may have hands-on classes at various learning environments, as long as there is a screen to mirror the instructor's computer and additional instructors for an individual approach. Furthermore, the tests can be both paper or computer-based ones.

\section{CONCLUSION}

Predoctoral students from our institution presented a comprehensive improvement in terms of correctly recognizing anatomical structures name and side, as well as MPR images identification generated via CBCT imaging, when comparing mid-term and end-term tests. This data may indicate that undergraduate students in our institution are qualified for properly prescribing and understanding CBCT images and reports provided by the oral and maxillofacial radiologist in their daily practice after graduation.

\section{ACKNOWLEDGEMENTS}

Funding was provided by $\mathrm{CNPq}$ National Council for Research, Brasília, Brazil, Ph.D. scholarship (to Solange KobayashiVelasco); and by CAPES - Coordination of the Advancement of Higher Education, Brasília, Brazil, Ph.D. scholarship (to Fernanda Cristina Sales Salineiro, Ivan Onone Gialain e Wellington Hideaki Yanaguizawa).

We would like to thank Anne Solutions (São Paulo, Brazil) for providing a software license that allowed us to transform DICOM images into proprietary files that the students could manipulate.

\section{RESUMO}

Conhecimento de estruturas anatômicas em 
imagens de tomografia computadorizada por feixe cônico - experiência de prática pedagógica O objetivo deste estudo foi relatar uma metodologia de ensino de tomografia computadorizada de feixe cônico (TCFC) aplicada a estudantes de graduação, avaliando o conhecimento de estruturas anatômicas do complexo dentomaxilofacial. Os estudantes foram orientados quanto às estruturas anatômicas e às aplicações clínicas da TCFC em aulas teóricas e práticas, compreendendo 45 horas de aula. Foram submetidos a duas avaliações, a primeira na metade do semestre, e a segunda no término do semestre. Os escores das avaliações (três variáveis: 1) nome, 2) lado - esquerdo/direito e 3) reconstruções multiplanares (RMP) - imagens ortogonais de identificação) foram comparados para verificar se houve melhora na aprendizagem. Testes de medianas e Wilcoxon compararam os exames intermediário e final. Os valores medianos para a variável 1 foram 6,0 (intermediário) e 8,0 (final). Em relação à variável 2 , a mediana variou de 9,0 (intermediário) a 10,0 (final). Quando os resultados da variável 3 foram analisados, ambas as medianas foram 10,0. Houve diferença significativa (teste de Wilcoxon, $\mathrm{p}<0,05$ ) quando foram comparados os exames intermediário e final, nas três categorias. Correlações lineares foram estabelecidas entre as três categorias e foram estatisticamente significantes para duas associações ("nome da estrutura anatômica" com "lado da estrutura anatômica" e "nome da estrutura anatômica" com "imagens da MPR"). Os estudantes de graduação apresentaram uma melhora em termos do reconhecimento correto das estruturas anatômicas, nome e lado, bem como imagens de MPR quando comparadas as duas avaliações.

Descritores: Educação em Odontologia. Tomografia Computadorizada por raios $\mathrm{X}$. Radiologia. Informática Médica.

\section{REFERENCES}

1. Adibi S, Zhang W, Servos T, O’Neill PN. Cone beam computed tomography in dentistry: what dental educators and learners should know. J Dent Educ. 2012;76
(11):1437-42.

2. Scarfe WC, Farman AG, Sukovic P. Clinical applications of cone-beam computed tomography in dental practice. $\mathbf{J}$ Can Dent Assoc. 2006;72(1):75-80.

3. Cavalcanti MGP. Cone beam computed tomographic imaging: perspective, challenges, and the impact of near-trend future applications. J Craniofac Surg. 2012;23(1):279-82.

4. Whitesides LM, Aslam-Pervez N, Warburton G. Cone-beam computed tomography education and exposure in oral and maxillofacial surgery training programs in the United States. J Oral Maxillofac Surg. 2015;73(3):522-8.

5. Carter L, Farman AG, Geist J, Scarfe WC, Angelopoulos C, Nair MK, et al. American Academy of Oral and Maxillofacial Radiology executive opinion statement on performing and interpreting diagnostic cone beam computed tomography. Oral Surgery, Oral Med Oral Pathol Oral Radiol Endodontology. 2008;106(4):561-2.

6. Kobayashi-Velasco S, Salineiro FCS, Gialain IO, Cavalcanti MGP. Diagnosis of alveolar and root fractures: an in vitro study comparing CBCT imaging with periapical radiographs. J Appl Oral Sci. 2017; 25(2): 227-33.

7. Parashar V, Whaites E, Monsour P, Chaudhry J, Geist JR. Cone beam computed tomography in dental education: a survey of US, UK, and Australian dental schools. J Dent Educ. 2012;76(11):1443-7. A

8. Murakami T, Tajika Y, Ueno H, Awata S, Hirasawa S, Sugimoto $M$, et al. An integrated teaching method of gross anatomy and computed tomography radiology. Anat Sci Educ. 2014;7(6):43849.

9. Shah P, Venkatesh R. Dental students' 
knowledge and attitude towards cone-beam computed tomography: an Indian scenario. Indian J Dent Res. 2016;27(6):581-5.

10. Kamburoglu K, Kursun S, Akarslan ZZ. Dental students' knowledge and attitudes towards cone beam computed tomography in Turkey. Dentomaxillofacial Radiol. 2011;40(7):439-43.

11. Slanetz PJ, Kung J, Eisenberg RL. Teaching radiology in the millennial era. Acad Radiol. 2013;20(3):387-9.

12. Machado JAD, Barbosa JMP, Ferreira MAD. Student perspectives of imaging anatomy in undergraduate medical education. Anat Sci Educ. 2013;6(3):163-9.

13. Lufler RS, Zumwalt AC, Romney CA, Hoagland TM. Incorporating radiology into medical gross anatomy: does the use of cadaver CT scans improve students' academic performance in anatomy? Anat Sci Educ. 2010;3(2):56-63.

14. Cui D, Wilson TD, Rockhold RW, Lehman MN, Lynch JC. Evaluation of the effectiveness of 3D vascular stereoscopic models in anatomy instruction for first year medical students. Anat Sci Educ. 2017;10(1):34-45.
15. Ravesloot CJ, Van Der Schaaf MF, Van Schaik JPJ, Ten Cate OTJ, Van Der Gijp A, Mol CP, et al. Volumetric CT-images improve testing of radiological image interpretation skills. Eur J Radiol. 2015;84(5):856-61.

16. Torres A, Staśkiewicz GJ, Lisiecka J, Pietrzyk Ł, Czekajlo M, Arancibia CU, et al. Bridging the gap between basic and clinical sciences: A description of a radiological anatomy course. Anat Sci Educ. 2016;9(3):295-303.

17. Al-Rawi W, Jacobs R, Hassan B, Sanderink G, Scarfe W. Evaluation of web-based instruction for anatomical interpretation in maxillofacial cone beam computed tomography. Dentomaxillofacial Radiol. 2007;36(8):459-64.

\section{Correspondence to:}

Marcelo Cavalcanti

e-mail: mgpcaval@usp.br

Av. Prof. Lineu Prestes, 2227

05508-000 São Paulo/SP Brazil 